\title{
Canais de comercialização da produção agroecológica: análise de uma propriedade em São Miguel do Iguaçu (PR)
}

Giovana Riva Maggi ${ }^{1}$ Marcio Roberto Ramos ${ }^{2}$ Cláudia Regina Oliveira ${ }^{3}$ Adriana Maria de Grandi ${ }^{4}$

\begin{abstract}
Resumo
O objetivo deste artigo é analisar os canais de comercialização de uma propriedade agroecológica. A propriedade analisada é considerada como modelo de agroecologia no Oeste do Paraná e está localizada no município de São Miguel do Iguaçu, no Paraná. A agroecologia é uma ciência que estabelece uma base teórica para os diferentes movimentos de agricultura não convencional. $A$ propriedade trabalha hoje com três canais de comercialização: o Programa de Aquisição de Alimentos (PAA), o Programa Nacional de Alimentação Escolar (PNAE) e o Turismo Rural. A metodologia adotada foi qualitativa, concebida por levantamento bibliográfico, aplicação de questionário semiestruturado e sistematização dos resultados e da análise dos dados. Pode-se concluir que a agroecologia, ao longo dos anos, vem ganhando espaço em setores da sociedade.
\end{abstract}

Palavras-chave: Agricultura familiar. Agroecologia. Desenvolvimento Rural. Canais de Comercialização.

\begin{abstract}
The aim of the paper is to analyze the marketing channels of agroecological property. The property is analyzed, considered as a model agroecology in West of Paraná and is located in São Miguel do Iguaçu. Agroecology is a science that establishes a theoretical basis for the different movements of non-conventional agriculture. The property is now working with three marketing channels PAA (Programa de Aquisição de Alimentos), PNAE (Programa Nacional de Alimentação Escolar) and Rural Tourism. The methodology was qualitative, designed by literature survey, application of semi-structured questionnaire and systematization of the results and data analysis. We can conclude that agroecology over the years has been gaining ground in sectors of society.
\end{abstract}

Keywords: Family Agriculture. Agroecology. Rural Development. Marketing Channels.

\footnotetext{
${ }^{1}$ Mestranda do Programa de Pós-Graduação em Desenvolvimento Rural Sustentável - Universidade Estadual do Oeste do Paraná (UNIOESTE) - Campus de Marechal Candido Rondon. giovana_riva21@hotmail.com

2 Mestrando do Programa de Pós-Graduação em Desenvolvimento Rural Sustentável - Universidade Estadual do Oeste do Paraná (UNIOESTE) - Campus de Marechal Candido Rondon.

${ }^{3}$ Mestranda do Programa de Pós-Graduação em Desenvolvimento Rural Sustentável - Universidade Estadual do Oeste do Paraná (UNIOESTE) - Campus de Marechal Candido Rondon.

4 Professora Doutora da Universidade Estadual do Oeste do Paraná (UNIOESTE) - Campus de Marechal Candido Rondon. adrianadegrandi@gmail.com
} 


\section{Introdução}

Ao se considerar a magnitude da agricultura familiar, no meio rural brasileiro, e, particularmente, os principais problemas enfrentados por esse segmento, constata-se que as políticas públicas voltadas para o desenvolvimento rural e, particularmente, para os pequenos agricultores familiares são de grande relevância, uma vez que grande parte dos pequenos municípios tem na agricultura a sua principal atividade econômica.

Como característica da agricultura familiar, tem-se a produção de alimentos, especialmente a voltada para o autoconsumo, ou seja, focalizam-se mais as funções de caráter social do que as econômicas, tendo em vista sua menor produtividade e incorporação tecnológica (FERNANDES, 2009).

Porém, apesar da produção se destacar como de subsistência, cada vez mais tem havido excedentes de produtos oriundos da agricultura familiar. O escoamento tem ocorrido de diversas formas, todavia o que tem recebido destaque, nos últimos anos, é a sensibilização dos produtores para aderirem aos programas nacionais, como o Programa Nacional de Alimentação Escolar (PNAE) e o Programa de Aquisição de Alimentos (PAA).

Para a maioria dos agricultores familiares, um dos únicos caminhos para desenvolver um mínimo de autonomia na comercialização de sua produção é criar um processo de vendas coletivo, porém nem sempre isso ocorre.

Assim, nesse processo de crescimento das atividades rurais não-agrícolas, especialmente no setor de agroecologia, este estudo tem por objetivo analisar os principiais canais de comercialização do Sítio Arruda, localizado no município de São Miguel do Iguaçu, no Estado do Paraná, que são PAA, PNAE e Turismo Rural.

\section{Agricultura familiar}

Durante a maior parte da história brasileira, a Agricultura Familiar foi um segmento quase inteiramente esquecido pelo Poder Público. A modernização da agricultura se deu em detrimento deste segmento, uma vez que as políticas públicas privilegiaram os produtores mais capitalizados: a esfera produtiva de commodities, voltadas ao mercado internacional, com fins de correção dos desequilíbrios dos pagamentos externos do país (MATTEI, 2001; DELGADO, 2005).

A trajetória do campesinato brasileiro reflete o processo de desenvolvimento socioeconômico do Brasil, moldado pela conformação da agricultura às exigências da economia colonial exportadora, pela existência de fronteiras agrícolas passíveis de posse livre e espontânea e, principalmente, pelos condicionamentos econômico, social e político exercido pela grande propriedade. Quando comparado à evolução do campesinato em outros países, foi um setor sistematicamente bloqueado, impedido de se desenvolver com plenas potencialidades como forma social específica de produção. Relegado à margem do desenvolvimento brasileiro, o campesinato também foi relegado a plano secundário na análise (WANDERLEY, 1995).

Na década de 1990, após o silêncio imposto pelo regime militar às lutas camponesas, é iniciado o processo de mudança desta situação, marcado por fortes reivindicações dos movimentos de trabalhadores e trabalhadoras do campo para a implementação de 
políticas públicas específicas para o setor (SCHNEIDER, 2003). Em 1996, foi implantado o Programa Nacional de Fortalecimento da Agricultura Familiar (PRONAF). Três anos depois, em 1999, criou-se o Ministério do Desenvolvimento Agrário (MDA), órgão da administração pública federal direta, que tem como competências legais a política de reforma agrária, as ações estatais de fomento à assistência técnica e extensão rural e a promoção do desenvolvimento sustentável do segmento econômico-social constituído pelos agricultores e agricultoras familiares (SIORG, 2008).

Finalmente, em julho de 2006, foi promulgada a Lei no 11.326 , que estabelece a conceituação oficial de Agricultura Familiar a ser utilizada pelas políticas públicas nacionais. Representou o reconhecimento pelo estado brasileiro do valor econômico e social da agricultura familiar para o país e da obrigação do poder público, independente da alternância programática de governos, para com seu fomento.

Segundo Wanderley (1996, p. 2), o conceito de agricultura familiar como categoria genérica é entendido como "aquela em que a família, ao mesmo tempo em que é proprietária dos meios de produção, assume o trabalho no estabelecimento produtivo". Esta combinação entre propriedade e trabalho, no entanto, assume, no tempo e no espaço, uma grande diversidade de formas sociais.

Para Schneider (2003), a pluriatividade, em princípio, diz respeito ao conjunto de atividades agrícolas e não-agrícolas desempenhadas por parte dos membros de uma família residente no meio rural. Segundo o autor, para entender a produção familiar, deve-se separá-la em "unidades familiares de produção" e "grupos domésticos", principalmente porque estes últimos devem englobar diversas relações, peculiaridades que não cabem na análise estritamente econômica.

O esforço da conceituação destes termos tem a intenção de fornecer subsídios ao debate sobre a importância da agricultura familiar no mundo, para orientar os aspectos analíticos, sociais e políticos, e, ainda, para propor questões de pesquisa.

No caso brasileiro, um esforço muito significativo tem sido feito desde os estudos sobre o Rurbano (DEL GROSSI; GRAZIANO DA SILVA, 2006), para compreender as transformações que o espaço rural vem sofrendo. Análises baseadas nos dados levantados pela Pesquisa Nacional por Amostra de Domicílios (PNAD) - revelam que o rural é caracterizado pela presença de um grande número de moradores desempenhando atividades não agrícolas. Por outro lado, registra-se o fenômeno da urbanização de famílias exercendo atividades agrícolas e de assalariados agrícolas e/ou pluriativos. De acordo com os autores, essa urbanização também é indicadora da necessidade das famílias de acesso a equipamentos urbanos, tais como educação, saúde, energia elétrica, lazer, entre tantas outras.

Entende-se que, apesar dos avanços alcançados em termos de elaboração teórica e também de políticas públicas, persistem alguns obstáculos ao pleno desenvolvimento da agricultura familiar. Os gargalos no escoamento da produção podem ser considerados um dos principais entraves. Permanece a importância de pesquisas e estudos sobre os mercados de comercialização desses produtos, os quais possam auxiliar no aperfeiçoamento tanto da ação pública quanto das decisões dos produtores individuais e associados. 


\section{Agroecologia}

A agroecologia é uma ciência surgida na década de 1970, como forma de estabelecer uma base teórica para esses diferentes movimentos de agricultura não-convencional. É uma ciência que busca o entendimento do funcionamento de agroecossistemas complexos, bem como das diferentes interações neles presentes, tendo como princípio a conservação e a ampliação da biodiversidade dos sistemas agrícolas como base para produzir autorregulação e, consequentemente, sustentabilidade (ASSIS, 2006). De acordo com Altieri (1998), na agroecologia, a produção sustentável deriva do equilíbrio entre plantas, solo, nutrientes, luz solar, umidade e outros organismos coexistentes.

A agroecologia propõe alternativas para minimizar a artificialização do ambiente natural pela agricultura. Apresenta uma série de princípios e metodologias para estudar, analisar, dirigir, desenhar e avaliar agroecossistemas. Utiliza-se um enfoque científico, que tem suas próprias ferramentas, teorias e hipóteses, o que lhe permite trabalhar no âmbito dos agroecossistemas e no desenvolvimento de sistemas agrícolas complexos e diversificados (ASSIS, 2006). Além disto, segundo o autor, na busca de autorregulação dos agroecossistemas como forma de atingir a sustentabilidade, a agroecologia não só enfatiza a importância dos parâmetros agronômicos e ecológicos, como também das questões socioeconômicas, resgatando o fato de que a agricultura, além de ser um processo ecológico, é um processo social, ou seja, o desenvolvimento tecnológico deve estar inserido num processo amplo, em que a tecnologia seja um instrumento rural que atenda às demandas sociais e econômicas.

O agroecossistema é produtivo e saudável, quando essas condições de crescimento ricas e equilibradas prevalecem, e quando as plantas possuem ou desenvolvem, a partir do manejo, tolerância a estresses e adversidades. Essa estratégia pode ser viabilizada com o desenho de sistemas produtivos complexos e diversificados, que pressuponham a manutenção de policultivos anuais e perenes associados com criações. A agroecologia propõe alternativas para minimizar a artificialização do ambiente rural pela agricultura, para o que apresenta uma série de princípios e metodologias para estudar, analisar, dirigir, desenhar e avaliar agroecossistemas. Utiliza-se de um enfoque científico, que tem suas próprias ferramentas, teorias e hipóteses, o que lhe permite trabalhar no âmbito dos agroecossistemas e no desenvolvimento de sistemas agrícolas complexos e diversificados (ASSIS, 2006).

A agroecologia, na medida em que possui como premissa básica uma produção agrícola que não agrida o meio ambiente, resgata a lógica da complexidade presente nas sociedades camponesas tradicionais, integrando propostas agroecológicas com outras voltadas ao desenvolvimento da agricultura familiar, a qual, em função da escala, favorece a conciliação entre a complexidade desejada e a supervisão e o controle do processo de trabalho necessários (ASSIS, 2006).

Sistemas agroecológicos, ao integrarem princípios ecológicos, agronômicos e socioeconômicos, surgem como possibilidade concreta de implementação de um processo democrático de desenvolvimento rural sustentável, a partir de uma ação local, na qual os agricultores tenham condições de assumir a posição de atores principais (ASSIS, 2006). Sendo assim, a agroecologia é um instrumento importante na implementação de estra- 
tégias para viabilizar produções agrícolas em pequena escala sob administração familiar, em função principalmente da baixa dependência de insumos externos dos sistemas de produção, que procuram manter, ou recuperar a paisagem e a biodiversidade dos agroecossistemas (AQUINO; ASSIS, 2007).

As possibilidades de realização bem-sucedida de pesquisas em agroecologia; da expansão e do aperfeiçoamento de cultivos agroecológicos; das atividades e do crescimento de movimentos que englobam os valores representados pelas finalidades da agroecologia (sustentabilidade, fortalecimento popular, etc.); e do redirecionamento das prioridades das instituições de pesquisa estão indissociavelmente interconectadas (LACEY, 2007).

\section{Turismo rural}

Há relatos que descrevem que o início do Turismo em Espaço Rural ocorreu no município de Lajes (SC), no final da década de 80 (PORTUGUEZ,1999). Contudo, outro estado do Brasil que deu início a esta atividade, na mesma época, foi o Espírito Santo, com o produtor Leandro Carnielli, e logo outras propriedades próximas aderiram à prática, o que levou este estado a criar o "Programa de Agroturismo" (CAMPANHOLA, 2000).

O Turismo Rural na Agricultura Familiar, é designado pela sigla TRAF, termo que, nos dias atuais, vem tomando força, acompanhado de outras designações, como agroturismo, ecoturismo, turismo esportivo, turismo cultural, entre outras, que tem revalorizado o território, grupos sociais rurais, e carreado um crescente fluxo de urbanistas (FROEHLICH, 2000).

Apesar do amplo número de termos usados para definir turismo rural, o conceito mais aceito atualmente é o definido pela Lei no 15.143 , de 31 de maio de 2006, o qual define que TRAF são todas as

atividades turísticas que ocorrem na unidade de produção dos agricultores familiares que mantêm as atividades econômicas típicas da agricultura familiar, dispostos a valorizar, respeitar e compartilhar seu modo de vida, o patrimônio cultural e natural, ofertando produtos e serviços de qualidade e proporcionando bem estar aos envolvidos (PARANÁ, 2006).

O TRAF mantém aspectos da ruralidade que se encontram ainda presentes em pequenas propriedades estruturadas a partir da ótica da produção familiar. Essas propriedades, por fatores diversos, como isolamento geográfico, manutenção de processos tradicionais de produção de alimentos, valorização das formas de tratamento entre familiares, entre outros, conseguem manter os aspectos da ruralidade (SCHNEIDER, 2006).

Neste sentido, o turismo passa a ser um forte aliado para manter as famílias no campo, configurando-se como uma possibilidade para melhorar os rendimentos de proprietários rurais e valorizar os modos de vida tradicionais, a ruralidade e o contato harmonioso com o ambiente natural. Os agricultores buscam no turismo uma complementação da renda, ou, muitas vezes, mudam a atividade original, configurando um novo uso do território, baseado no patrimônio histórico, no cultural e no arquitetônico (GUZZATTI; TURES, 2011).

Além da valorização do espaço rural e da agregação de renda à família, o TRAF 
e outros termos que envolvem o turismo rural também contemplam a preservação do ambiente, e todos juntos fazem parte da estrutura atrativa para a propriedade. $\mathrm{O}$ agroturismo, na sua importância para o meio rural, desenvolve atividades voltadas para a sustentabilidade, tendo por metas resguardar e envolver a população residente, preservar os recursos naturais e culturais, envolver instituições públicas e empresas privadas e gerar renda (PARRA, SILVA; CHEHADE, 2006).

\section{Canais de comercialização}

Entende-se por comercialização a troca de bens e serviços entre agentes econômicos. O fruto dessas trocas são as transações, que podem ser consideradas a unidade fundamental da análise do funcionamento do sistema econômico (ZYLBERSZTAJN, 2000). Os bens fluem pelos canais de comercialização e de distribuição - arranjos intrincados ou diretos - que conduzem as mercadorias do produtor ao consumidor final e, quanto maior a coordenação entre os componentes do sistema, menores serão os custos de transação associados.

Como observa Wilkinson (2003), os estudos sobre a dinâmica da agricultura familiar revelam marcada polivalência das suas formas comerciais. Entre os limites da subsistência e da entrada em sistemas produtivos especializados, está presente a combinação de vários arranjos, desde atividades tipicamente de autoconsumo, trocas entre vizinhos, vendas diretas e atividades que incorporam circuitos formais de comercialização e distribuição, até aquelas relacionadas com a agroindústria, por meio dos contratos de integração.

Segundo Zylbersztajn (2000), na economia familiar, também são muito importantes as formas não-monetárias de comércio, apesar de o assunto ser pouco estudado.

Vendas diretas: todas as operações de entrega direta da mercadoria ao consumidor final pelo produtor, tais como entregas a domicílio, tele-entregas, feiras livres, feiras especializadas, eventos comerciais promocionais, loja, balcão ou quiosque do produtor, vendas na propriedade;

Integração vertical: venda de produtos como matéria-prima para beneficiamento pelo comprador (os principais produtos no Brasil são leite, fumo, tomate, suínos e aves).

Vendas para distribuição: atacadistas, varejistas, distribuidores, restaurantes, lojas especializadas de agricultura orgânica e produtos naturais, supermercados e hipermercados, exportação.

Mercados institucionais: um exemplo são os mercados criados pelo Programa de Aquisição de Alimentos da Agricultura Familiar (PAA, Lei no 10.696, de 2 de julho de 2003). O PAA é um instrumento de política pública que realiza a compra de produtos da agricultura familiar. A aquisição é feita por diferentes modalidades, sendo as principais: 1) compra para o atendimento de populações em situação de insegurança alimentar e nutricional, com distribuição em escolas, creches, hospitais públicos, restaurantes populares, entre outros; 2) formação de estoques estratégicos. 
O PAA, criado em julho de 2003 pela Lei no 10.696/03, é uma política pública desenvolvida para incentivar a agricultura familiar, promover a inclusão social no campo e garantir alimento às populações em situação de insegurança alimentar, por meio da compra da produção familiar (BRASIL, 2011).

O PAA se propõe a ser uma ação estruturante dentro do Programa Fome Zero, a fim de gerar estabilidade à atividade socioeconômica da agricultura familiar. Segundo o Governo Federal, ao comprar a produção, ele garante preço justo e renda aos agricultores, reduz o preço das cestas destinadas aos programas sociais e facilita o processo de doação de alimentos (BRASIL, 2011). De acordo com o Ministério do Desenvolvimento Social, as principais oportunidades do PNAE para a Agricultura Familiar são:

- Capacidade de produção da agricultura familiar como fornecedora de alimentos diversificados e de qualidade;

- Sensibilização crescente das prefeituras para vislumbrar o PNAE como instrumento de desenvolvimento local;

- Conscientização crescente da sociedade para a necessidade de hábitos alimentares saudáveis, preservação das tradições alimentares locais e da produção com baixo impacto ambiental.

As políticas públicas voltadas para o setor agrário, em especial a agricultura familiar, têm desempenhado papel importante na intervenção do processo produtivo e comercial dos produtos agrícolas. A implementação do PAA e do PNAE pôde garantir pela prefeitura local e pelos conselhos das escolas estaduais a compra da produção familiar, possibilitando maior estabilidade à atividade agrícola, garantindo ocupação e renda ao produtor em seu próprio local, incentivando a permanência e a inclusão social no campo e proporcionando melhores condições de vida (BRASIL, 2011).

Dessa forma, o agricultor e sua família passam a desenvolver a atividade de forma mais ampla e sistemática, explorando com maior racionalidade o espaço rural.

Um fator importante para a execução desses programas no município são os incentivos à produção por meio de assistência técnica, distribuição de sementes, o que proporciona ao homem do campo condições de trabalho, produção e renda.

Os resultados do programa indicam que, ao assegurar a remuneração e o escoamento da produção - melhorando a oferta de alimentos baratos e saudáveis para as populações urbanas - são impulsionados o fortalecimento da agricultura familiar e a inclusão social no campo (BRASIL, 2011).

\section{Resultados e discussão}

Foi realizado um estudo de caso na propriedade agroecológica "Sitio Arruda", localizado no município de São Miguel do Iguaçu, no Estado do Paraná. Didaticamente, o trabalho foi dividido em três etapas: a etapa inicial, quando se realizou o levantamento bibliográfico. Foram realizadas pesquisas bibliográficas por meio de livros e periódicos nacionais, dispostos em acervo virtual, e em bases de dados, onde foram selecionados 
e consultados artigos publicados, originais e de revisão sobre o tema. A segunda fase do trabalho foi da observação direta, proporcionando a convivência real dos pesquisadores com o cotidiano das famílias do local, utilizando equipamentos de áudio e vídeo, fotos e aplicação de questionário semiestruturado. A terceira e última etapa teve como base uma abordagem qualitativa, desenvolvendo a sistematização dos resultados e a análise dos dados.

A entrevista semiestruturada é uma entrevista feita a partir de um roteiro de perguntas previamente elaborado, quando se quer obter informações a respeito de um assunto específico (RUAS et al., 2006), mas que é feita de maneira bem informal, funcionando mais como um diálogo através do qual duas pessoas estão se conhecendo. É necessário, porém, preparar com antecedência um guia de entrevista, para ser usado como orientação, sendo que este guia não deve conter mais do que dez a quinze perguntas (KUMMER, 2007), pois a maioria das perguntas surge no decorrer da própria entrevista. A entrevista semiestruturada foi uma ferramenta importante para o conhecimento mais aprofundado da realidade da propriedade.

O objetivo deste artigo constitui em analisar os canais de comercialização de uma propriedade agroecológica, considerada como modelo de agroecologia. Esse estabelecimento rural, que atualmente produz em torno de 40 espécies, principalmente hortaliças, pupunha, café in natura, mamão, banana, acerola, goiaba, maracujá, cítricos, abacate, manga entre outros, foi adquirida em 2001 por Luiz Antonio Arruda, com um total de 5 hectares, onde antes era produzido, de modo convencional, milho, soja, entre outras culturas.

Incentivado pelo Programa Cultivado Água Boa (CAB), na Bacia do Paraná 3, e pensando na responsabilidade socioambiental, o proprietário iniciou a produção orgânica, e hoje é certificada pela IBD - Inspeções e Certificações Agropecuárias e Alimentícias, que antes de ser modificada somente produzia com agrotóxicos. No local, há uma agroindústria, onde os frutos são transformados em polpa, e a produção, em grande parte, é vendida para os programas institucionais PAA e PNAE, garantindo às crianças e consumidores um alimento saudável e livre de agrotóxicos.

A oportunidade de um mercado institucional, para apoiar e fortalecer a agricultura familiar local, contribuindo para diminuir a insegurança do agricultor familiar quanto à comercialização da sua produção, pode melhorar a renda da família, bem como contribuir para a sua permanência no meio rural.

O PNAE se fortalece como política de governo, com grande capacidade para influenciar o desenvolvimento local. Sua sinergia com políticas que fortalecem a agricultura familiar pode desencadear um próspero e virtuoso ciclo para o desenvolvimento local como promotores da segurança alimentar e nutricional.

De acordo com um agricultor familiar entrevistado na pesquisa, "O produtor produzia e não tinha a quem vender. O PNAE, quando chegou, foi a garantia de receber, e, se a gente sabe que vai receber, a gente pode plantar para vender mais". O canal de comercialização foi o desdobramento da institucionalização do mercado institucional e fez circular mais recursos no meio rural. O depoimento evidencia um princípio de desenvolvimento local e um importante impacto do PNAE nesse desenvolvimento e na segurança alimentar das famílias rurais. A geração de maior renda aos agricultores familiares 
ocasiona um aumento do poder aquisitivo, que leva a maior fluxo financeiro e novos investimentos em produção.

Os agricultores que recebem estes recursos pela venda de seus produtos passam a ter uma capacidade de consumo maior e mais estável, o que incentiva o investimento dos agricultores, que é feito em grande parte dentro do próprio município. Esse ciclo de dinamização econômica é uma expressão essencial do desenvolvimento local.

Outro canal de comercialização é o turismo rural; o Sítio Arruda, incentivado pelo Programa Cultivando Água Boa (CAB), faz parte de um Circuito de Turismo regional que reúne quatro propriedades de São Miguel do Iguaçu: todos os meses, o circuito recebe em média duzentos turistas. Com visitas pré-agendadas e geralmente direcionadas pela Itaipu e Universidades, a propriedade recebe visitantes de várias partes do mundo, interessados em conhecer como funciona uma propriedade familiar sustentável.

Uns dos grandes atrativos da propriedade é uma agrofloresta, que possui uma trilha de aproximadamente 800 metros, onde os visitantes conhecem cerca de oitenta culturas diferentes, produzidas no mesmo espaço, onde natureza e produção andam juntas, sem agressão ou degradação do solo, da fauna ou da flora. Para a recepção dos visitantes, a família oferece alimentação caseira orgânica, valorizando a cultura dos alimentos da agricultura familiar.

\section{Conclusões}

Diante do exposto ao longo desta pesquisa, podemos concluir que a agroecologia, ao longo dos anos, vem ganhando espaço em setores da sociedade. A necessidade de uma agricultura sustentável tem levado à busca de novas estratégias, para que se possa promover um desenvolvimento "socialmente justo", "economicamente viável" e "ecologicamente equilibrado".

Neste sentido, a agricultura orgânica apresenta-se como uma opção viável para inserção dos agricultores familiares no mercado, viabilizando a prática das bases do Desenvolvimento Sustentável, visto que esta pode resgatar antigas e construir novas formas de relação socioambiental, baseadas na cooperação, na solidariedade e no respeito à vida.

Neste cenário de tendências para mudanças e permanências das situações e conflitos do mundo rural, emergem novas soluções e formas de sustentabilidade, novas racionalidades sobre a agricultura do futuro, que deverá estabelecer vínculos mais estreitos com o homem e com a Terra.

\section{Referências}

ALTIER, M. A. Agroecologia - a dinâmica produtiva da agricultura sustentável. Porto Alegre UFRGS, 1998.

ASSIS, R. L. Desenvolvimento rural sustentável no Brasil: perspectivas a partir da integração de ações públicas e privadas com base na Agroecologia. Revista Economia Aplicada, v. 10, n. 1. Ribeirão Preto, jan./mar. 2006. 
AQUINO, A. M.; ASSIS R. L. Agricultura orgânica em áreas urbanas e periódicos urbanas com agroecologia. Ambiente \& Sociedade, v. 10, n. 1, p. 137-150, 2007.

BRASIL. Ministério do Desenvolvimento Social e Combate à Fome. PAA 5 anos: balanço e perspectivas. 2011. Disponível em: <http://www.mds.gov.br/sites/seminario-paa-balanco-e-perspectivas>. Acesso em: 4 abr. 2014.

CAMPANHOLA, C. O. Agroturismo como fonte de renda para o pequeno agricultor brasileiro. In: ALMEIDA, J. A.; RIEDL, M. Turismo rural: ecologia, lazer e desenvolvimento. Bauru: Edusc, 2000. p. 145-179.

DELGADO, L. A questão agrária no Brasil, 1950-2003. In: RAMOS, L. R.; ALY, O. J. (Eds.) Questão agrária no Brasil: perspectiva histórica e configuração atual. São Paulo: Instituto Nacional de Colonização e Reforma Agrária, 2005.

DEL GROSSI, M. E.; GRAZIANO DA SILVA, J. Movimentos recentes da Agricultura Familiar. Cadernos do CEAM, Brasília, v. 6, n. 24, p. 91-102, 2006.

FERNANDES, Ângela Esther Borges. O Perfil da Agricultura Familiar Brasileira. 2009. Disponível em: <http://www.webartigos.com/articles/16496/1/O-perfil-da-agriculturafamiliar brasileira/pagina1.html.Webartigos.com>. Acesso em: 5 maio 2014.

FROEHLICH, J. M. Turismo rural e agricultura familiar: explorando (criticamente) o cruzamento de abordagens e estratégias para o desenvolvimento. In: ALMEIDA, J.; RIEDL, M. (Orgs.). Turismo Rural: ecologia, lazer e desenvolvimento. Bauru: Edusc, 2000. p. 181-197.

GUZZATTI, T. C.; TURES, V. A. O papel da Associação de Agroturismo. Acolhida na Colônia (SC) na construção de políticas públicas de turismo focadas no desenvolvimento rural e na promoção da agricultura familiar. V ENAPGS - Encontro Nacional de Pesquisadores de Gestão Social, Florianópolis, maio 2011.

KUMMER, L. Metodologia participativa no meio rural: uma visão interdisciplinar conceitos, ferramentas e vivências. Salvador: GTZ, 2007.

LACEY, H. Há alternativas ao uso dos transgênicos? Novos Estudos. 2007. Disponível em: <http://www.scielo.br/scielo.php?pid=S0101-33002007000200005\&script=sci_ arttext>. Acesso em: 4 abr. 2014.

MATTEI, L. Programa Nacional de Fortalecimento da Agricultura Familiar (PRONAF): Concepção, abrangência e limites observados. Texto apresentado no IV Encontro da Sociedade Brasileira de Sistemas de Produção, realizado em Belém (PA), de 19 a 23 de março de 2001.

PARRA, C. S.; SILVA, C. P.; CHEHADE, M. B. Agroturismo como fonte de renda para pequenos agricultores. Revista Científica Eletrônica Turismo, ano 3, n. 5, p. 1-7, jun. 2006.

PARANÁ. Lei no 15.143, de 31 de maio de 2006. Define as atividades turísticas que especifica, como atividades de "Turismo Rural na Agricultura Familiar". Curitiba (PR): Diário Oficial, 2006.

PORTUGUEZ, A. P. Agroturismo e desenvolvimento regional. São Paulo: Hucitec, 1999. 
RUAS, Elma Dias et al. Metodologia participativa de extensão rural para o desenvolvimento sustentável: MEXPAR. Belo Horizonte: Governo do Estado de Minas Gerais, 2006.

SCHNEIDER, S. Teoria social, Agricultura Familiar e pluriatividade. Revista Brasileira de Ciências Sociais, v. 18, n. 51, p. 99-122, fev. 2003.

. Turismo em Comunidades Rurais: inclusão social por meio de atividades não-agrícolas. In: BRASIL. Ministério do Turismo. Turismo social, diálogos do turismo: uma viagem de inclusão. Rio de Janeiro: Instituto Brasileiro de Administração Municipal, 2006. p. 264-293.

SIORG. Sistema de Informações Organizacionais do Governo Federal. 2008. Disponível em: <http://www.siorg.redegoverno.gov.br/index1_1.asp?Tipo=1>. Acesso em: 10 abr. 2014.

WANDERLEY, M. N. B. A Agricultura Familiar no Brasil: um espaço em construção. Reforma Agrária, Campinas, v. 25, n. 2/3, p. 37-57, 1995.

. Raízes Históricas do Campesinato Brasileiro. In: TEDESCO, J. C. (Org.). Agricultura Familiar Realidades e Perspectivas. 2. ed. Passo Fundo: EDIUPF, 1996. p. 21-55.

WILKINSON, J. A pequena produção e sua relação com os sistemas de distribuição. In: Anais do Seminário Políticas de Seguridad Alimentaria y Nutrición en América Latina. Campinas: UNICAMP, 2003.

ZYLBERSZTAJN, D. Economia das Organizações. In: ZYLBERSZTAJN, D.; NEVES, M. F. (Orgs.) Economia e Gestão dos Negócios Agroalimentares. São Paulo: Pioneira, 2000. 